\title{
Medical management of unruptured interstitial pregnancy with mifepristone and methotrexate
}

\section{Karki U', Saha R²}

'Usha Karki, MD Resident; ${ }^{2}$ Rachana Saha, Professor; Department of Obstetrics and Gynaecology, Kathmandu Medical College Teaching Hospital, Kathmandu, Nepal

\begin{abstract}
Ectopic pregnancy is a serious complication of pregnancy in which embryo gets implanted any where other than the uterine cavity. In interstitial pregnancy; the pregnancy is located in that part of the fallopian tube that penetrates the muscular layer of the uterus. Overall incidence of ectopic pregnancy is one to two percent among which the incidence of interstitial pregnancy is only two percent. Interstitial pregnancy being the hazardous type requires immediate management. Though surgical treatment is the management of choice, its association with decreased fertility rate and increased rate of uterine rupture in future pregnancy cannot be ignored. We hereby report of medical management of interstitial ectopic pregnancy with single oral dose of-Mifepristone $200 \mathrm{mg}$ along with single dose of Methotrexate 50miligram intramuscularly.
\end{abstract}

Key words: Ectopic pregnancy, Fertility rate, Interstitial Pregnancy, Medical management

\section{INTRODUCTION}

G ctopic pregnancy occurs when a blastocyst implants Cany where other than the endometrial lining of the uterus. Approximately one to two percent of all pregnancies is ectopic, and is the most common cause of pregnancy-related mortality in the first trimester, and account for three to four percent of maternal mortality ${ }^{1}$. Of all the ectopic pregnancies, interstitial pregnancies account for two to four percent and can be associated with a mortality rate in the range of $2.0-2.5 \%^{2}$. In case of interstitial pregnancy there is a concern for uterine rupture secondary to the weakened myometrial wall, the rupture of cornu still may result in life-threatening massive haemorrhage despite advances in both diagnosis and therapy. The major mortality and morbidity is directly related with late onset of symptoms and late diagnosis.

Management of Interstitial pregnancy basically follows a three-pronged approach: expectant management, awaiting spontaneous resolution, medical treatment, and surgical treatment by laparoscopy or laparotomy ${ }^{3}$.

\section{Address for correspondence}

Dr. Usha Karki

Department of Obstetrics and Gynaecology

Kathmandu Medical College Teaching Hospital

Kathmandu, Nepal

E-mail: bibnum@hotmail.com
While expectant management can be applied only in a few selected cases, which account for a very small proportion of the female population with ectopic pregnancies, medical treatment is now considered a good alternative to surgery especially in cases where fertility needs to be preserved. Several drugs have been suggested in literature for medical treatment. Among them, Methotrexate administered systemically seems to offer the greatest benefits in terms of efficacy and tolerability 4 .

Since Injection Methotrexate was first used for ectopic pregnancy treatment, it has proved to be a good alternative to surgical procedures in selected cases of ectopic pregnancy ${ }^{5}$. Mifepristone is a synthetic steroid compound with both antiprogesterone and antiglucocorticoid activity which is being used widely as an abortifacient agent.

We hereby present a rare case of an interstitial pregnancy which was successfully managed medically with single dose of Tablet Mifepristone 200mg along with Injection Methotrexate 50mg intramuscularly, thus obviating the need for a surgical intervention.

\section{CASE REPORT}

A 26 year old primigravida, referred from private hospital presented at Kathmandu Medical College Teaching 
Hospital on $21^{\text {st }}$ July 2013 with complain of amenorrhoea for 9 weeks with intermittent per vaginal bleeding, moderate in amount since 1 month. On examination patient was conscious and her blood pressure, pulse, respiratory rate and SPO2 were within normal limit. On abdomino-pelvic examination, uterus was six weeks size with slight right adnexal tenderness was present. No guarding or rebound tenderness was noted. Obstetrical ultrasound revealed thick hyper echoic wall with cystic area in centre measuring $16.3 \mathrm{~mm}$ in the right cornua of the uterus without embryo or yolk sac, consistent with 5 weeks 1 day pregnancy (Figure 1). MRI done also revealed the same findings as of Ultrasound (Figure 2). No free fluid was noted at the cul-de-sac. The patient was diagnosed to have unruptured interstitial pregnancy and admitted.

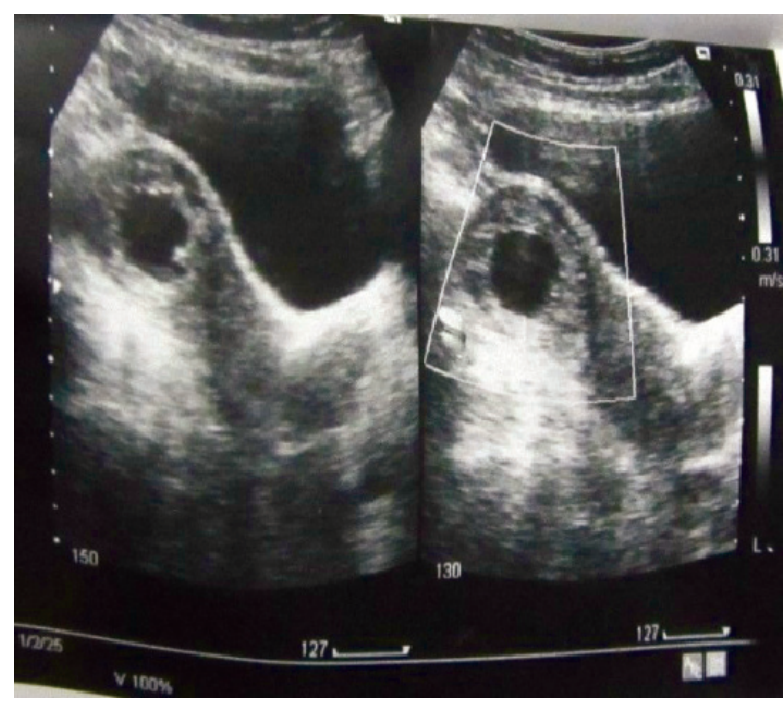

Figure 1: Pelvic ultrasonography of the patient

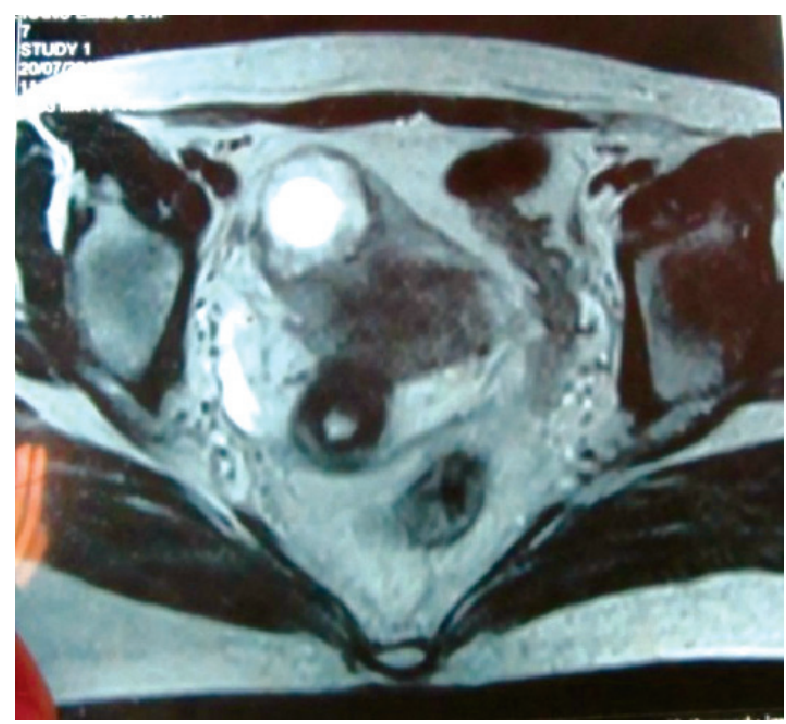

Figure 2: MRI pelvis of the patient.

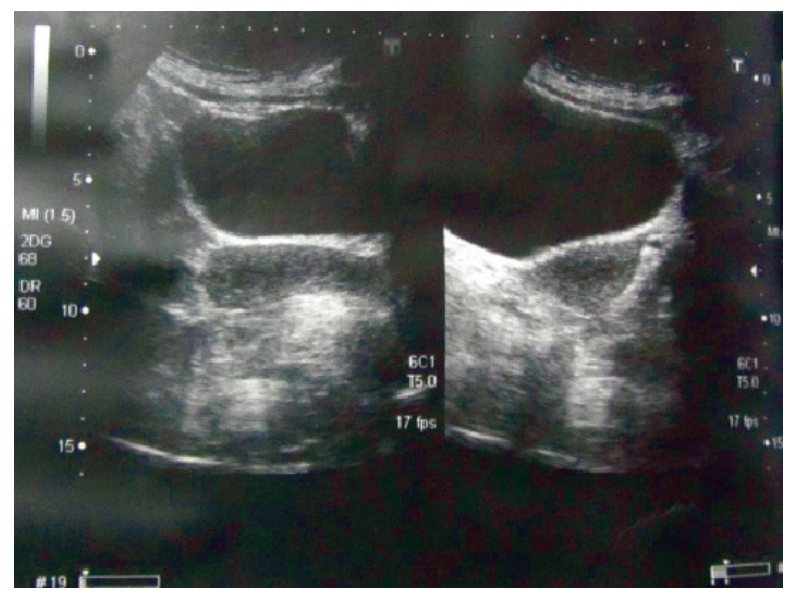

Figure 3: Pelvic ultrasonography of the patient

First laboratory findings were: serum $\beta$-hCG level was $594.8 \mathrm{mlU} / \mathrm{ml}$, hemoglobin $13 \mathrm{~g} / \mathrm{dL}$ and other biochemical laboratory findings like renal function test, liver function test were normal. The patient was counselled about surgical resection or Methotrexate therapy of the ectopic pregnancy. She preferred medical management. So single dose of Tab Mifepristone $200 \mathrm{mg}$ per orally was given along with a single dose of intramuscular Methotrexate $(50 \mathrm{mg}$ ) was administered. On the 4th day after Methotrexate administration, serum $\beta$-hCG concentration was $464.1 \mathrm{mIU} / \mathrm{mL}$. On the 7 th day after Methotrexate administration, serum $\beta$-hCG concentration was $339.8 \mathrm{mlU} / \mathrm{mL}$. The patient was taken to follow-up for weekly serum $\beta$-hCG measurements. After one week, serum $\beta$-hCG concentration was 307 $\mathrm{mIU} / \mathrm{mL}$. The other weekly serum $\beta$-hCG concentrations were $291 \mathrm{mlU} / \mathrm{mL}, 289.6 \mathrm{mlU} / \mathrm{mL}, 15 \mathrm{mlU} / \mathrm{Ml}$ and 3.7 $\mathrm{mIU} / \mathrm{ml}$ respectively. Patient was on follow up twice after her serum $\beta$-hCG was within normal limit. Follow up Ultrasound was done which revealed completely resolved right sided interstitial mass. (Figure 3)

Patient resumed her normal menstrual cycle 45 days after her last normal serum $\beta$-hCG level.

\section{DISCUSSION}

Diagnosis of interstitial pregnancies relies heavily on ultrasound and on laparoscopic evaluation ${ }^{6}$. A viable interstitial pregnancy may occasionally be misinterpreted as a normal intrauterine pregnancy. Therefore, it is important that strict diagnostic criteria are used in every case: empty uterine cavity and chorionic sac that is seen separately and more than $1 \mathrm{~cm}$ from the most lateral edge of the uterine cavity and surrounded by a myometrial layer?

Traditionally interstitial pregnancies have been 
diagnosed late and managed by open surgery ${ }^{8}$. Only a small number of case reports have described medical treatment of interstitial ectopic pregnancies ${ }^{9,10}$. Almost all of the reported patients were treated with repeated high doses $(1 \mathrm{mg} / \mathrm{kg})$ of Methotrexate ${ }^{9,10}$.

The treatment should performed surgically if the patient is hemodynamically unstable, serum hCG is $>10,000 \mathrm{mlU} /$ $\mathrm{mL}$, the ectopic pregnancy is $4 \mathrm{~cm}$ or more in diameter, if there is a medical contraindication to Methotrexate, and if the patient may not be followed adequately after treatment. Medical treatment should be preferred if the patient has undergone surgery many times previously, has extensive pelvic adhesion, a contraindication for general anesthesia, and after failure of a conservative laparoscopic treatment. Medical treatment is possible if serum hCG is below 5,000 or $10,000 \mathrm{mlU} / \mathrm{mL}$, if the ectopic pregnancy is less than $4 \mathrm{~cm}$ in diameter or if the score is adequate when a scoring system prospectively evaluated can be used. Medical treatment should be preferred if hCG $<1000 \mathrm{mlU} / \mathrm{mL}$, if the patient has no pain and if the ectopic pregnancy cannot be visualized at ultrasound.

Likewise the rationale behind treating the patient mentioned in above case report was status of patient as she was haemodynamically stable, status of pregnancy which was at early weeks of gestation and was unruptured also patients wish to go for medical treatment and remain under regular follow up. Although there are reports of successful treatment with single-dose Methotrexate injection; and also reports of failures ${ }^{9-12}$. Fisch et al. concluded that Methotrexate is a safe option but the failure rate is high ${ }^{8}$. So close monitoring is essential because rupture is possible even after treatment has begun and a longer follow-up is required. Patient must be informed about extended follow-up.

\section{CONCLUSION}

Patients meeting the criteria, for conservative treatment, should be considered for medical treatment Single dose Methotrexate is cost effective and alternative to traditional surgical management of interstitial pregnancy. In the hemodynamically stable patient Methotrexate is a safe option and may be the first line treatment in the management of unruptured interstitial pregnancy. Surgery can be avoided however a longer and close follow-up is required. Haemodynamic stability is the most important criteria and this directly correlated with the early diagnosis in early gestational age.

\section{REFERENCES}

1. Berg CJ, Callaghan WM, Syverson C, Henderson Z. Pregnancy-related mortality in the United States, 1998 to 2005. Obstet Gynecol 2010;116:1302-9.

2. Faraj, Steel. Management of cornual(interstitial) pregnancy.The Obstetrician and Gynaecologist. October 2007; 9 (4):249-55.

3. Görük. Treatment of cornual viable pregnancy. JClinExp Invest 2012; 3 (1): 105-107

4. C. Merisio, S. Anfuso, R. Berretta, M. Gualdi, D.C. Pultrone, M. Melpignano.Single-dose methotrexate for ectopic pregnancy treatment:preliminary data. ACTA BIO MED2005; 76: 33-36

5. Tanaka T, Hayashi H, Fujimoto S, Ichinoe K. Treatment of interstitial ectopic pregnancy with methotrexate: report of a successful case.FertilSteril.1982; 37: 851-2

6. MacRae R, Olowu O, Rizzuto MI, Odejinmi F. Diagnosis and laparoscopic management of 11 consecutive cases of cornual ectopic pregnancy. Arch GynecolObstet. 2009;280(1):59- 64.

7. Timor-Tritsch IE, Monteagudo A, Matera C, Veit C. Sonographic evaluation of corneal pregnaacies treated without surgery. ObstetGynecol.1992;79(6):83-7.

8. Katz D L. Barrett J P. Sanfilippo J S. Badway D M. Combined hysteroscopy and laparoscopy in the treatment of interstitial pregnancy. Am J ObstetGynecol. 2003;188(4):1113-4.

9. Fisch J D. Ortiz B, Tazuke S, Chitkara U, Giudice L. Medical management of interstitial ectopic pregnancy: a case report and literature review. Hum Reprod.1998;13(7):1981-6.

10. Gherman RB, Stitely M, Larrimore C, Nevin K, Coppola A, Wiese D. Low-dose methotrexate treatment for interstitial pregnancy. A case report.J Reprod Med.2000;45(2):142-4.

11. Jermy K, Thomas J, Doo A, Bourne T. The conservative management of interstitial pregnancy.BJOG 2004;111(11):1283- 8

12. Larraín D, Marengo F, Bourdel N, Jaffeux $P$, et al. Proximal ectopic pregnancy: a descriptive general population-based study and results of different management options in 86 cases. FertilSteril. 2011;95(3):867-71. 